\title{
RELAÇÃO EMPRESA-FAMÍLIA: O PAPEL DA MULHER
}

\author{
Maria Cecília Coutinho de Arruda \\ Professora do Departamento de Mercadologia e Coordenadora do CENE \\ (Centro de Estudos de Ética nos Negócios) da EAESP/FGV. \\ E-mail: carruda@eaesp.fgvsp.br
}

\begin{abstract}
Este artigo foi publicado originalmente sob o título La Mujer entre el hojar e la empresa, in: MELÉ, Domenec (coord.). Empresa y vida familiar. Barcelona: IESE Universidad de Navarra, 1995 p. 147-160
\end{abstract}

RESUMO: Na relaçāo empresa-familia, o papel da mulher se revela preponderante. Por lei natural, o homem, por meio de seu trabalho, deve obter os recursos necessários para seu próprio sustento e o de sua familia. A mulher, com o casamento, passa a ser a companheira do marido, cabendo-lhe a missão de zelar pela direçāo material e moral da familia, a primeira formaçāo de caráter e educaçāo dos filhos. Para isso, faz-se necessária sua presença no lar. As empresas vêm tomando medidas que denotam a valorizaçāo da mulher, quer no quadro de empregados, quer como esposa de um funcionário.

ABSTRACT: In the relationship business-family, the women's role has shown to be very important. According to the natural law, the man - through his work - must obtain the resources he needs for his own and his family's survival. Once married, the woman becomes her husband's partner, with the mission of managing the family, either materially or morally, the first character formation and the children's education. This requires her presence at home. Companies have adopted policies that express how valuable a woman can be for the organization, either as an employee herself, or as an employee's wife.

PALAVRAS-CHAVE: familia, empresa, mulher, valor, trabalho.

KEYWORDS: family, business, women, value, professional work. 
Por estar tão de perto ligado à vida, torna-se relevante o estudo de todo o entrelaçamento das múltiplas relações intra e extra familiares. Sem dúvida, a família representa "o núcleo natural e fundamental"1 da sociedade, como expressou muito apropriadamente um conhecido professor brasileiro: "todo homem, ao nascer, torna-se membro integrante de uma entidade natural: o organismo familiar. A ela conserva-se ligado durante a sua existência, embora venha a constituir nova família pelo casamento"

Ao definir a família como seminarium republicae, Cícero procurava mostrar que, onde e quando ela se mostrou forte, aí floresceu o Estado. Em contrapartida, onde e quando se revelou frágil, aí começou a decadência geral ${ }^{3}$.

Portanto, se a salvação do Estado, a prosperidade da vida temporal e a formação do homem honesto se encontram nas mãos da família, todo esforço é pouco para resgatar sua importância. Fenômenos como o da menor responsabilidade para o pai, menor abnegação da esposa, menor respeito dos filhos, entre outros, que se dão em muitos países do mundo atual, revelam que há problemas que exigem uma análise profunda e urgente. Não é nosso propósito confrontar aqui esta análise: estaria fora de lugar e excederia nossas capacidades; mas gostaríamos de contribuir com algumas considerações sobre o papel da mulher na relação empresa-família à luz dos ensinamentos sociais da Igreja Católica enfocando o panorama que se vislumbra a partir do Brasil, um país em via de desenvolvimento, ainda que com um grande potencial de crescimento.

\section{O PAPEL DA MULHER NA RELAÇÃO EMPRESA-FAMILIA}

O papel da mulher na relação empresafamília está condicionado pela própria situação da mulher, que sofreu não poucas vicissitudes ao longo da história. Há muito a mulher é relegada a um plano secundário; desde o direito romano, "ela se acha$v a$ in manus do esposo ... Por outro lado, enquanto os homens se reservavam as atividades mais nobres, como a guerra, a navegação, o comércio, as letras e as artes, deixavam as mulheres com os trabalhos mais pesados e menos elevados"4. Aristóteles, Schopenhauer,

Weininger e outros filósofos, assim como diversos homens de Estado de notável influência, trataram a mulher com inferioridade e desdém. Foi o Cristianismo que primeiramente ressaltou a dignificação da mulher e glorificou a maternidade. Nos tempos atuais, a civilização foi completando e aperfeiçoando essa "obra redentora" ${ }^{\text {" }}$.

Nenhuma sociedade humana - e aqui incluímos expressamente a empresa pode admitir o permissivismo em questões relevantes como as que se referem ao

Nenhuma sociedade humana - e aqui incluímos expressamente a empresa - pode admitir o permissivismo em questões relevantes como as que se referem ao respeito pela essência do casamento e da família, ao valor dos filhos e ao papel que a mulher desempenha no seio da família.

respeito pela essência do casamento e da família, ao valor dos filhos e ao papel que a mulher desempenha no seio da família. "A Igreja - afirma João Paulo II na Carta às Famílias - defende com energia a identidade da familia e exorta às instituições competentes, especialmente aos responsáveis pela política, assim como às organizações internacionais, a não cair na tentação de uma aparente falsa modernidade"6. Entre estas instituições competentes, a empresa ocupa um lugar destacado. Nesse mesmo documento, o Romano Pontífice se refere também à necessidade de que o trabalho da mulher no lar seja reconhecido e valorizado ao máximo: "A fadiga da mulher - que depois de haver dado à luz um filho, alimenta-o, cuida dele e se ocupa de sua educação, especialmente em seus primeiros anos -é tão grande que não se deve temer o confronto com nenhum trabalho profissional. É preciso afirmar isto claramente, não menos do que a maneira como se reivindica qualquer outro direito relativo ao trabalho. A maternidade, com todos os esforços que comporta, deve obter também um reconhecimento econômico igual, ao menos, ao que é dado aos demais trabalhos enfrentados para manter a família em uma fase tão delicada de sua existência"7.
1. Declaraçāo universal dos direitos humanos, Art. 16, 3 .

2. MONTEIRO, Washington de Barros. Curso de Direito Civil. São Paulo: Saraiva, 1980, v. 2, p. 1

3. Idem, ibidem.

4. Idem, ibidem, p. 131.

5. Idem, ibidem.

6. JOÃO PAULO II, Carta às Famílias, ne 17.

7. Idem, ibidem. 
8. PIO XI, Encíclica Casti connubi, 31 dez. 1930.

9. Idem, ibidem.

10. Exh. Apost. Familiaris consortio, n. 22. João Paulo II, se ocupou da dignidade da muIher de modo exaustivo na Carta Apostólica Mullieris dignitatem, de 15 de agosto de 1988 , e especialmente nos nos 6 a 9 deste documento.

11. Idem, ibidem, $n^{2} 23$.

12. Idem, ibidem.

13. Encíclica Laborem exercens, $\mathrm{n}^{\circ} 19$
A valorização do papel da mulher como mãe tem sido continuamente ressaltada pela doutrina social da Igreja. Já em 1930, o Papa Pio XI alertava para a questão da emancipação da mulher, mostrando que "os mestres do erro ... defendem com arrogância que a emancipação da mulher deve ser tríplice: no governo da sociedade doméstica, na administração dos bens da família e na exclusāo ou supressão da prole, isto é, social, econômica e fisiologicamente. Fisiológica, enquanto querem que a mulher, em harmonia com sua vontade, seja ou deva ser livre dos encargos de esposa, quer conjugais, quer maternos. Emancipação econômica, em virtude da qual a mulher, mesmo sem conhecimento ou contra a vontade do marido, possa livremente ter, gerir e administrar os seus negócios privados, desprezando os filhos, o marido e toda a família. Emancipaçāo social, por último, enquanto se afastam da mulher os cuidados domésticos, tanto dos filhos como da familia em conjunto, para que, eliminados estes, possa entregar-se às suas inclinações naturais e consagrar-se às funçōes e negócios públicos"8.

Pio XI advertia sobre o caminho da corrupção que esta emancipação pode estar sugerindo, pois é contrária à verdadeira, razoável e digna liberdade que convém à mulher cristã, afastando-a de sua nobre missão de esposa. Trata-se, pois, da corrupção da condição feminina, da dignidade materna e da perversāo de toda a família, enquanto o marido fica privado de sua mulher, os filhos da sua mãe, a casa e a família de sua sempre vigilante guarda. A própria mulher desce daquele trono real a que foi elevada pelo Evangelho, caindo rapidamente na antiga escravidão que a transforma num simples instrumento do homem, como no paganismo?.

Esta firme defesa do papel da mulher no lar - como esposa e como mãe - não significa, no entanto, que a mulher não deva trabalhar em uma empresa ou exercer cargos públicos, nem que a Igreja não defenda com firmeza a igualdade entre o homem e a mulher na dignidade humana e nos direitos fundamentais que ambos têm como pessoas: "Criando o ser humano, homem e mulher(Gen. 1, 27), Deus dá a dignidade pessoal de igual modo ao homem e à mulher, enriquecendo-os com os direitos inalienáveis e com as responsabilidades que sāo próprias da pessoa humana"10. Esta igual dignidade e responsabilidade de homem e mulher "justificam plenamente o acesso da mulher às funçōes públicas"11.

Junto a uma igualdade fundamental existem também diferenças que configuram a identidade característica da masculinidade e da feminilidade. Estas diferenças nāo estão radicadas em certas "imagens" da mulher construídas sobre a base de diferenças estereotipadas: o homem seria racional, ativo, dominante, enquanto a mulher se apresentaria sentimental, passiva, submissa. A mulher sabe pensar com lógica, da mesma forma que o homem está chamado a realizar-se na entrega. Assim, a idêntica responsabilidade social do homem e da mulher justifica plenamente o acesso desta às tarefas públicas.

Por natureza, o diferencial entre os dois sexos reside naquilo que não é passível de mudança: só a mulher pode ser mãe, e só o homem pode ser pai. É verdade que o homem e a mulher geram em comum, porém a mulher se empenha muito mais na maternidade, particularmente na fase prénatal. Conclui-se que o pai deva ser consciente de que tem especiais obrigações para com sua esposa, colaborando nas tarefas de casa, assim como a mulher também o ajuda a ganhar a vida. Por isso, um programa sério para a igualdade de direitos deverá levar estes pontos em consideração.

Atualmente, em vários países, as condições sociais e econômicas da mulher transformaram-se concomitantemente às mudanças de usos e costumes da sociedade. Nesse caso, em que a mulher passa a integrar a empresa para suas tarefas profissionais, cabe ao poder público adaptar às necessidades e exigências atuais os direitos civis da mulher, pautando-se sempre na índole natural do sexo feminino, na honestidade dos costumes e no interesse comum da família.

Em outras palavras, tanto na vida profissional quanto empresarial, social e política, a promoção da mulher precisa passar por um efetivo reconhecimento de igualdade de direitos com o homem. Mais do que isso:"a verdadeira promoção da mulher exige também que seja reconhecido o valor de sua função materna e familiar com respeito às demais funções públicas e às outras profissōes"12 e que "o trabalho se estruture de maneira que (a mulher) nāo deva pagar sua promoção com o abandono do caráter específico próprio e em prejuízo da família"13. 
Logo, a empresa, assim como outras instituições sociais, deve zelar para que a ordem essencial da sociedade doméstica permaneça intacta, como instituída por Deus, e portanto não passível de mudanças por leis públicas ou pela vontade dos indivíduos. A solução está em encontrar fórmulas adequadas que permitam harmonizar as distintas funções da mulher. A conclusão do Romano Pontífice é muito clara: "tais funções (maternas, familiares, públicas) hão de integrar-se entre si, se se quiser que a evolução social e cultural seja verdadeira e plenamente humana"14.

A vida familiar requer recursos econômicos cuja principal fonte para a imensa maioria de pessoas é o trabalho. A remuneração do trabalho deve ser suficiente para o trabalhador e para sua família. A justiça no salário é tão importante que em Palavras de João Paulo II - constitui "uma verificação autêntica da justiça de todo o sistema sócio-econômico (...). Tal verificação afeta, sobretudo, a família. Uma justa remuneração do trabalho de uma pessoa adulta que tem responsabilidades de familia será aquela que seja suficiente para fundar e manter uma familia e assegurar seu futuro" ${ }^{\prime 15}$. Para facilitar as funções maternas e familiares, e também como um efetivo reconhecimento de seu valor, a Igreja insiste na importância de que as mães de família não tenham necessidade econômica de trabalhar fora de casa ${ }^{16}$. Isto pode ser especialmente agudo no caso de mulheres com famílias numerosas, com crianças pequenas, e mais ainda nas que estão separadas e têm filhos a seu cargo. Umas palavras de Pio XI, escritas há mais de sessenta anos, têm ainda grande atualidade em muitos países em desenvolvimento:"Se (...) as mães de familia, com grande prejuizo da economia doméstica, estão sobrecarregadas pela necessidade e pela exigência de ganhar dinheiro à custa do próprio trabalho, se aos trabalhos comuns ou mesmo extraordinários da maternidade falta o alimento conveniente, os medicamentos, o auxílio de um médico competente ou outros problemas semelhantes: não há ninguém que não perceba quão dificil se torna para elas a vida doméstica e a observância dos preceitos divinos, e também quão grande perigo comporta para a segurança pública, para a salvação e a vida da própria sociedade civil, se tais homens, não tendo já a quem recorrer, fossem levados a um desespero tão grande que tentassem talvez chegar a uma subversão social ou do próprio Estado"17.
Trata-se, pois, da corrupção da condição feminina, da dignidade materna e da perversão de toda a família, enquanto o marido fica privado de sua mulher, os filhos da sua mãe, a casa e a família da sua sempre vigilante guarda.

\section{O TRABALHO DA MULHER: NA FAMÍLIA OU NA EMPRESA?}

Tem-se insistido muito na necessidade de que a mulher trabalhe fora de casa para que possa "realizar-se". Neste contexto, ao falar de "realizar-se", com freqüência se pensa em obter êxito profissional ou satisfazer os próprios desejos. A plenitude humana - conceito mais preciso que "realizar-se" - certamente não é o mesmo que êxito profissional. Tem mais a ver com desenvolvimento de virtudes que possibilitem a auto doação amorosa aos demais, o que pode acontecer na empresa, mas com maior facilidade ocorre na família.

Na realidade, o trabalho feminino no lar e na empresa não tem por que ser incompatível. De fato, nota-se por parte de não poucas um esforço para tornar compatível o trabalho na empresa e no lar. Além disso, em alguns países, os governos procuram dar maior apoio à maternidade. No entanto, é preciso reconhecer que o trabalho fora de casa apresenta não poucos problemas para viver a maternidade de modo responsável.

Do ponto de vista sociológico, constatam-se certos indícios que fazem pensar em uma mudança de tendência na valorização relativa do trabalho na empresa e na família.

\section{Dedicação total à família}

Nos Estados Unidos, verifica-se uma tendência crescente das mulheres deixarem a profissão para dedicar-se integralmente à família. O Departamento do Trabalho constatou que, pela primeira vez desde 1948, a percentagem de mulheres que trabalham não ultrapassou os $45,3 \%$ em 1990. A dona de casa parece estar perdendo a imagem de "figura antiquada" que lhe vinha sendo atribuída. Sete anos atrás, criou-se uma associação de mães que
14. Exh. Apost. Familiaris consortio, $n^{0} 23$.

15. Encíclica Laborem exercens, $\mathrm{n}^{2} 19$.

16. Idem, ibidem.

17. PIO XI, Encíclica Casti connubi, 31 dez. 1930. 
renunciaram ao emprego, e em 1992 já contava com 1.250 membros. A entidade, denominada Female, visava dar apoio às mulheres que desejavam trocar o emprego pelo lar, geralmente uma passagem difícil, por ir contra a corrente, supondo uma perda de consideração social, amizades e, é claro, renda.

Um livro recente, escrito por Sanders e Bullens, parece indicar que $71 \%$ das norte-americanas $-63 \%$ das quais trabalham fora de casa - opinam que é benéfico aos filhos que um dos pais não tenha trabalho externo, sempre que as necessidades econômicas o permitam. Muitas manifestam interesse em voltar a trabalhar quando os filhos forem maiores. Outras opinam que o lar pode ser um lugar de atividade profissional. Cerca de $20 \%$ das entrevistadas abriram um negócio em sua casa ou pensam em fazê-lo. Algumas continuaram como consultoras das empresas em que trabalhavam, e houve até quem transformasse um antigo hobby em profissão ${ }^{18}$. A experiência dos Estados Unidos parece mostrar uma volta aos princípios éticos antes analisados sobre a mulher e o seu papel na família.

\section{Trabalhos no domicílio}

Preocupado em criar emprego e em atender às necessidades das famílias, 0 governo francês concede, desde 1992, vantagens fiscais para a promoção dos trabalhos no domicílio. Novos incentivos, ainda que não concretizados, vão estender-se às pessoas que cuidam de crianças em seu domicílio. Simone Weil, a ministra de Assuntos Sociais deste país, quer simplificar o sistema assistencial com esta medida. Considera "emprego familiar", além do cuidado de crianças, anciãos ou inválidos, qualquer outra tarefa doméstica que não concorra com as empresas comerciais de conservação, jardinagem, consertos etc. Em 1992, as famílias já podiam obter $50 \%$ de seus gastos com este novo conceito, até um total de 13 mil francos. Segundo estimativas de 1993, até o final de 1992 surgiram 92 mil empregos: uns $60 \mathrm{mil}$ provenientes de pessoas que já realizavam trabalhos domésticos não declarados, enquanto o resto foi resultado de nova criação ${ }^{19}$.

Esta iniciativa, ainda que aparentemente não estimule a volta da mulher ao lar, facilita sua presença em casa. Espera-se que as pessoas que consigam este tipo de emprego, sobretudo as mulheres, obtenham com estas medidas um complemento salarial que as ajude $\mathbf{a}$ alcançar uma vida mais digna, ou uma melhor qualidade de vida, com um horário mais flexível e conveniente para o cuidado de filhos e marido, do que se trabalhassem em uma empresa.

\section{Possibilidades das pequenas e médias empresas}

Muitas famílias vêem no seu próprio negócio uma forma de poder compartilhar o tempo com filhos, cônjuge e demais atividades de um lar. Em empresas familiares, pequenas ou médias, os filhos vão crescendo e são atendidos no próprio recinto da organização, além de sua residência. Por isso, os incentivos e subsídios para criar pequenas empresas supõem, indiretamente, uma ajuda à família e à permanência da mulher no lar.

Muitos governos se equivocam quanto ao destino de recursos, em fase de desemprego. Mais que dar subsídios às multinacionais, que atualmente absorvem quase $95 \%$ desses recursos, deveriam destinalos à criação de pequenas e médias empresas, hoje aquinhoadas com somente $5 \%$ do total. Anualmente, os países ocidentais contribuem com 60 bilhões de dólares para as empresas multinacionais, só repartindo 1 bilhão entre as pequenas e médias, dificultando, dessa forma, a criação de empregos.

Em 1986, na Itália, criou-se uma Agência, dotada com um orçamento de $782 \mathrm{mi}-$ lhões de dólares, para atender aos projetos de novas empresas organizadas por jovens de 18 a 35 anos - período de grande importância para a formação de novas familias. Nos quatro anos seguintes, foram aceitos mais de 4 mil projetos, e cada selecionado receberia em média 1,7 milhão de dólares. A prioridade recaiu sobre o setor industrial, por gerar mais empregos que $o$ setor de serviços. Cada nova empresa conta com um "tutor", oriundo de um quadro de 700 experts, que the transmite a cultura organizacional e lhe dá conselhos oportunos. Carlo Borgomeo, presidente da Agência italiana para jovens empresários, viu nascer, com essa lei, um total de 875 novas empresas, com 18 mil empregados. Essas 
pequenas e médias empresas têm em média 20 assalariados, e o seu principal êxito foi que, cinco anos após ficar sem subsídio estatal, $80 \%$ delas continuaram operando de forma satisfatória ${ }^{20}$.

Nos Estados Unidos, o governo acaba de aprovar a constituição de um importante fundo para financiar a criação de empresas em zonas totalmente carentes de recursos naturais.

$\mathrm{Na}$ Suécia, o incentivo a pequenas e médias empresas se fez mais necessário que nunca, uma vez que muitas empresas voltadas à exportação ou ao investimento no exterior reduziram o seu ritmo tradicional de criação de empregos. A pesada carga tributária das empresas impede que as pequenas e médias possam crescer acima de um determinado patamar, o que não estimula sua permanência no mercado.

\section{Incentivos à natalidade}

O envelhecimento da população européia é um fenômeno conhecido. Os casais não têm mais do que um ou dois filhos, apesar de, em alguns países, existirem subsídios governamentais. No entanto, curiosamente, na Suécia vão aumentando as taxas de natalidade, em relação a outros países. Em 1993, a média de filhos por mulher na Espanha era 1,23; na Itália, era de 1,26 , enquanto na Irlanda e na Suécia eram, respectivamente, de 2,11 e 2,17.

O caso da Suécia merece especial atenção, já que registrou um notório aumento desde a taxa de 1983, que era de 1,6 filhos/ mulher, até a atual. Em 1983 nasceram 91 mil crianças, enquanto em 1990 houve 122 mil nascimentos.

Birgit Arve-Pares, que coordena as atividades do Ano Internacional da Família no Ministério dos Assuntos Sociais da Suécia, explica que "não se trata de fazer com que nasçam mais crianças, mas de facilitar sua inserção social". Algumas medidas aplicadas na Suécia são: licença para um dos pais permanecer em casa durante um ano após o nascimento do filho, recebendo $90 \%$ do salário, e mais três meses com uma compensação menor; criação de diversos trabalhos de tempo parcial; subsídios familiares substanciosos, proporcionais ao número de filhos; creches e pré-escolas subvencionadas de $84-89 \%$; financiamento de $85 \%$ dos gastos com colégios particulares,

ou ensino gratuito na rede oficial. Naturalmente, os impostos pagos ao Governo pelos cidadãos suecos equivalem a $52 \%$ de sua renda, estando entre os mais elevados do mundo ${ }^{21}$.

\section{O CASO DO BRASIL}

Com freqüência, em países subdesenvolvidos como o Brasil, a sociedade ainda não conseguiu que o Estado evite, ou minimize, as ameaças à ordem social. Há sérios problemas não somente em razão de salários insuficientes, mas também de moradia, higiene e saúde, entre outros. No entanto, há também muitos aspectos positivos. O Papa João Paulo II, em sua viagem ao Brasil em 1980, ressaltou vários deles, sobre os quais pode se apoiar a restauração do conceito de família como transmissora de valores culturais, éticos e espirituais:"Nos admira que aqui (no Brasil) se manifeste, com singular valor, o sentido da família e se confirmem as dimensões essenciais

\section{Esta firme defesa do papel da mulher no lar - como esposa e como mãe - não significa, no entanto, que a mulher não deva trabalhar em uma empresa ou exer- cer cargos públicos, nem muito menos que a Igreja não defenda com firmeza a igual- dade entre o homem e a mulher na digni- dade humana e nos direitos fundamentais que ambos têm como pessoas.}

da realidade familiar: o respeito impregnado de amor e de ternura, a generosidade e o espírito de solidariedade, e o apreço por uma certa intimidade do lar, temperado por um desejo de abertura"22.

\section{A mulher no Brasil, na família e na empresa}

A legislação brasileira vem caminhando lentamente no sentido do fortalecimento da família e da promoção da mulher. A Lei ${ }^{\circ} 4121$, de 27 de agosto de 1962, seguindo as recomendações internacionais, dispõe sobre a situação jurídica da mulher casada, eliminando tudo o que anterior-
20. Cf. Aceprensa, no 17, Servicio 68/94, 11 mar. 1994.

21. Cf. Aceprensa, Servicio $57 /$ 94, 27 abr. 1994.

22. A Palavra de João Paulo II no Brasil: discursos e homilías. São Paulo: Edições Paulinas, 1980, p. 47. 
mente se reconhecia como inferioridade jurídica e social da mulher ${ }^{23}$.

Embora hoje seja comum afirmar que os direitos da mulher são iguais aos do homem perante a lei, na realidade brasileira isto não ocorria deste modo. Até há pouco, o código civil brasileiro incluía a mulher casada entre as pessoas relativamente incapazes, ao lado dos menores, dos pródigos e dos silvícolas (art. $6^{\circ}$ ), não podendo sequer exercer uma profissão ${ }^{24}$. Competia ao marido a chefia da sociedade conjugal. Desta maneira, tanto na própria família como nos assuntos domésticos, existia uma unidade diretiva ou uniformidade de orientação. Tal unidade, porém, não fica comprometida com o correspondente nivelamento jurídico da mulher no plano da capacidade civil, pois há uma autoridade judiciária para dirimir os conflitos que possam se manifestar no âmbito familiar $^{25}$.

Com o casamento, a mulher passa a ser considerada companheira, consorte e colaboradora do marido nos encargos da família, cabendo-lhe a missão de zelar pela direção material e moral desta ${ }^{26}$.

Uma vez constituída a família, segundo Consentini, a mulher se converte no verdadeiro "elo", cuja influência se revela essencial, primordialmente na primeira formação do caráter e da educação dos filhos. Dela dependem, ao mesmo tempo, a economia e a prosperidade da família, a concórdia e a harmonia, que asseguram a elevação e o bem-estar da famíliaa ${ }^{27}$.

Atualmente, pelo código civil brasileiro, a mulher que exercer profissão lucrativa, distinta da do marido, terá direito de praticar todos os atos inerentes ao seu exercício, bem como sua legítima defesa. Seu direito exclusivo ao produto de seu trabalho "visa a um fim de amparo e proteção, $e$ decorre de uma verdadeira imposição social"28.

Portanto, do ponto de vista legal, fica

23. MONTEIRO, W. B.. Op. cit., p. 132.

24. Idem, ibidem, p. 130.

25. Idem, ibidem.

26. Código Civil Brasileiro, artigo 240 , com a redação dada pela Lei $n^{0} 6515$ de 26 de dezembro de 1977 , artigo $5^{\circ}, n^{2} 5$.

27. Le Droit de Famille, p. 13.

28. MONTEIRO, W. B.. Op. cit., p. 132. das Leis Trabalhistas: obrigatoriedade do afastamento da mulher grávida por três meses; salário durante $o$ afastamento; descanso para amamentação do filho; escolas maternais e jardins-de-infância; berçário, saleta de amamentação, cozinha dietética e instalação sanitária, creches e outros benefícios que, normalmente, não são concedidos por falta de recursos financeiros do Estado.

Segundo dados da Fundação Instituto Brasileiro de Geografia e Estatística (IBGE), em 1980, 36\% das mães brasileiras trabalhavam. Em 1989, na Grande São Paulo, $41 \%$ das mães participavam da força de trabalho. Em 1990, 20,3\% das famílias brasileiras eram chefiadas por mulheres.

\section{Possibilidades das empresas}

É impressionante o contraste existente entre a abundância de bens e serviços disponíveis no Primeiro Mundo e o inadmissível atraso nos países do Terceiro Mundo, mais concentrados no sul, faixa geopolítica em que vive a maior parte da humanidade. A crise de saúde e habitação, a disponibilidade de água potável, a distribuição de alimentos, as condições de emprego-especialmente feminino, o desemprego ou subemprego, o problema demográfico, a dívida internacional, os confrontos políticos e ideológicos, e muitos outros aspectos, parecem indicar a existência de um fosso entre os países desenvolvidos e os subdesenvolvidos.

As empresas, enquanto orientadas ao bem comum, não podem depender somente dos objetivos de lucro, em detrimento do bem público. Isso seria desprezar as necessidades materiais dos seus funcionários, esquecendo que eles também são cônjuges e chefes de família. Embora não possam individualmente solucionar todos os problemas sociais e econômicos que afligem os países, torna-se imperioso aos dirigentes de empresas aliviar a penúria das famílias de seus empregados mais pobres, na certeza de que este é um dos principais deveres de seu cargo. Ao mesmo tempo, estes dirigentes não devem eludir os esforços para que as leis sejam mais justas e eqüitativas em matéria de previdência social. Neste campo, é lamentável o que se observa em relação ao trato de muitas mulheres que trabalham na empresa.

Uma visão economicista, inspirada apenas na acumulação de bens, não estará 
contribuindo para uma justiça social mais profunda. Assim como o superdesenvolvimento gera consumismo - uma praga dos tempos atuais, a propaganda também fomenta um consumo elevado, supérfluo e mesmo abusivo, enquanto sabemos que há milhões de pessoas que passam fome ${ }^{29}$.

Em relação ao trabalho da mulher, há que destacar diversas empresas brasileiras que facilitam o trabalho das mães empregadas oferecendo serviços de creche, horário flexível, possibilidade de trabalhar em casa etc.

A Incepa, indústria cerâmica, 2.500 funcionários, $20 \%$ mulheres, tem creche para crianças de 3 meses a 6 anos; oferece alimentação, fraldas, assistência médica, atendendo a 120 crianças; as mães têm dois intervalos no período de trabalho para amamentar seus filhos.

A Avon, indústria de cosméticos, 2.500 funcionários, $52 \%$ mulheres, tem berçário para crianças de até 1 ano e 2 meses, incluindo alimentação e fraldas; ocupa-se da formação profissional de filhos de funcionários com menos de 14 anos; oferece licença remunerada para a mãe em caso de enfermidade do filho, quando este exige internação.

A Azaléia, indústria de calçados, $6 \mathrm{mil}$ funcionários, $35 \%$ mulheres, tem creche para crianças com até 6 anos, e centros de educação complementar para as que freqüentam a escola regular; possui três intervalos de 45 minutos durante a jornada para mães que amamentam; estuda a possibilidade de tornar flexíveis os horários das áreas administrativas e de recursos humanos.

A Kodak Brasileira, indústria eletrônica, 2.600 funcionários, $18 \%$ mulheres, monta escritórios na casa dos funcionários do setor de vendas - com mesa, cadeira, computador, impressora, linha telefônica e secretária eletrônica.

$\mathrm{A} A B B$, indústria eletrônica, 2.600 funcionários, $11 \%$ mulheres, tem um esquema de horário flexível para alguns departamentos; o funcionário pode chegar até uma hora e meia atrasado, ou finalizar sua jornada meia horas antes, compensando nos dias seguintes, cede vagas de estacionamento dos altos executivos, que estão mais próximas da fábrica, para as mulheres grávidas ${ }^{30}$.

\section{Ações políticas}

Por outro lado, o respeito aos direitos humanos, especialmente ao da vida, vem sendo objeto de consideração pelos governos e pelas empresas. A absorção de tecnologia obsoleta e inútil por parte dos países subdesenvolvidos, com frequiência, denota uma falta de adequação aos acordos internacionais de proteção ao meio ambiente ou à segurança humana. Em contrapartida, as empresas hão de procurar a auto-afirmação de cada pessoa, facilitando-lhe, na medida de suas possibilidades, mais cultura, mais informação, alfabetização e educação de base, assim como o necessário ao sustento e a uma vida digna. Estes e muitos outros aspectos foram objeto de profunda análise pelo Papa João Paulo II em sua Encíclica Sollicitudo rei socialis ${ }^{31}$.

\section{CONCLUSÃO}

Na relação empresa-família, o papel da mulher adquire cada vez maior preponderância. Por lei natural, o ser humano, homem ou mulher, por meio de seu trabalho, deve obter os recursos necessários para seu próprio sustento e o de sua família. A mulher, com o casamento, passa a ser companheira do marido e, quando for o momento, mãe. Em palavras de João Paulo II: "a força moral da mulher, sua força espiritual, une-se à consciência de que Deus lhe confia de modo especial o homem; quer dizer, o ser humano. Naturalmente, cada homem é confiado por Deus a todos e a cada um. No entanto, esta entrega se refere especialmente à mulher - sobretudo por sua feminilidade $-e$ isso decide principalmente sua vocação" $0^{\prime \prime}$.

A atividade da mulher no lar tem uma importância primordial na direção material e moral da família, e a formação inicial do caráter e a educação dos filhos. Para isso, faz-se necessária sua presença no lar.

A ausência da mãe de família de seu lar, somente entendida por causas econômicas sérias, deve ser minimizada pelas iniciativas das empresas e por uma legislação adequada e justa.

As empresas estão adotando medidas que revelam a valorização da mulher, quer como funcionária, quer como esposa de um funcionário.
29. No Brasil, estima-se em 30 milhões 0 número de pessoas consideradas indigentes ou em um nivel de miséria absoluta.

30. NESTLEHNER, Wanda. Mamãe trabalha, mamãe é. Claudia, São Paulo: Editora Abril, p. 146-51, jul. 1994.

31. Especialmente nos capítulos III, IV e V desta encíclica.

32. Carta Apostólica Mullieris dignitatem, ne 30 . 